\title{
Molecular Structure of Poplar Lignin Obtained by $p$-Toluene Sulfonic Acid ( $p$-TsOH) and Formic Acid Delignification
}

\author{
Songlin Wang, ${ }^{\mathrm{a}, \mathrm{b}, *}$ Zongjia Song, ${ }^{\mathrm{b}}$ Hui He, ${ }^{\mathrm{a}}$ and Qian Wang ${ }^{\mathrm{b}}$ \\ Poplar wood sawdust was chemically modified and separated into fractions \\ using a mixture of $p$-toluene sulfonic acid ( $\mathrm{p}-\mathrm{TsOH}$ ) and formic acid under \\ different conditions. The optimum conditions of poplar lignin separation were \\ determined by single-factor experiment. The mixed acid lignin (MAL) and the \\ solid residues were subjected to comprehensive structural characterization \\ by Fourier-transform infrared spectroscopy (FTIR), proton nuclear magnetic \\ resonance $\left({ }^{1} \mathrm{H}-\mathrm{NMR}\right), \mathrm{X}$-ray diffraction (XRD), and scanning electron \\ microscope (SEM). At the mass ratio of $5: 1$ of $\mathrm{p}-\mathrm{TsOH}$ and formic acid, \\ temperature of $80{ }^{\circ} \mathrm{C}$, acid concentration of $75 \%$, and reaction time of 20 \\ min, more than $80 \%$ of lignin was removed, and almost all of the cellulose \\ was retained in the solid residue. The results indicated that the $p$ - \\ $\mathrm{TsOH} /$ formic acid achieved rapid and nearly-complete dissolution of wood \\ lignin below the water boiling temperature by enhancing the cleavage of \\ interunitary bonds in lignin ( $\beta-\mathrm{O}-4^{\prime}$ bond) and the 4-hydroxy-3-methoxy \\ cinnamic acid structure in the lignin.
}

Keywords: Lignin; p-Toluenesulfonic acid; Formic acid; Separation; FTIR; SEM; Crystallinity index

Contact information: a: Guangxi Key Laboratory of Clean Pulp \& Papermaking and Pollution Control, College of Light Industry and Food Engineering, Guangxi University, Nanning 530004; b: College of Marine Science and Biological Engineering, Shandong Provincial Key Laboratory of Biochemical Engineering, Qingdao University of Science \& Technology, Qingdao, Shandong 266042 China;

* Corresponding author: wangsongl@126.com

\section{INTRODUCTION}

As the most abundant biopolymer after cellulose present in lignocellulosic biomass, lignin is expected to play an important role in the production of renewable high-value added chemicals and new materials. The three-dimensional network structure of lignin is formed by three types of phenylpropane units connected by ether and carbon-carbon bonds.

In addition to its use as heavy oil viscosity reducer, high temperature baking agent, dispersing agent in concrete, and oil-water coagulant, etc. (Dessbesell et al. 2020), lignin has significant aromaticity, and it can be used to produce biofuels ( $\mathrm{Bi}$ et al. 2015), hydrogels (Thakur et al. 2017; Sathawong et al. 2018), adsorbent materials (Supanchaiyamat et al. 2019), urea formaldehyde adhesives, surfactants, and various polymer composites (Thakur et al. 2014). In recent years, the separation and utilization of lignin has attracted attention from academic and industrial researchers (Yuan et al. 2013; Kumar et al. 2020). Acid (Yasuda et al. 2001), alkali (Sipponen et al. 2013), supercritical liquid (Pasquini et al. 2005), electrochemical methods (Haddad et al. 2017), ionic liquid (Achinivu et al. 2014; Achinivu 2018), and gels (Cai et al. 2001) are widely used in academic laboratories to separate lignin from biomass.

Nearly all commercial lignin products come from sulphite pulping, and the spent liquor is called "brown liquor". However, the lignin obtained has a broad molecular weight 
distribution and does not have a constant thermal transition temperature (Yuan et al. 2009; Rautiainen and Alén 2010). These drawbacks limit the lignin for further development and utilization. Acid is also widely used for delignification. Acid lignin includes Klason lignin, periodate lignin, phosphoric acid lignin, etc. Significant chemical structure modification of Klason lignin makes it difficult for further utilization. Lignin from periodate delignification is usually over-oxidized. However, acid lignins are only produced in lab-scale quantities, but they are not commercially produced. The only "acidic lignin" commercially produced is lignosulphonate.

Organic solvent lignin is easily prepared with minimal degradation (Zhao et al. 2009). New lignocellulosic fractionation technologies using organic solvents, which can easily be recovered and reused, such as alcohols, organic acids, cresols, and phenols, have been developed to obtain cellulose, hemicelluloses, and lignin without serious degradation (Zhang et al. 2017). Among the organic solvents, formic acid used in organosolv fractionation process demonstrates high efficiency on different biomass materials. It can simultaneously separate cellulose, hemicelluloses, and lignin and allow further conversion of fractions into value added chemicals and materials (Kupiainen et al. 2012). Fractionation of lignocellulose by acetic and formic acid conducted at atmospheric pressure and above the water boiling temperature $\left(>100{ }^{\circ} \mathrm{C}\right)$ achieved $96 \%$ lignin removal from wheat straw (Snelders et al. 2014), 88.9\% lignin removal from bamboo (Li et al. 2012), and 85\% lignin removal from rice straw (Lam et al. 2001). Increasing the reaction pressure yields higher degrees of delignification than the treatment of the same raw material at atmospheric pressure (Dapía et al. 2000). However, using a high temperature and pressure with organic solvents means that the process requires a high energy input and causes environmental issues, which in turn, impedes commercial deployment of the technology.

$p$-Toluene sulfonic acid ( $\mathrm{p}-\mathrm{TsOH})$ is an organic acid with strong reactivity and low price. It is a good solvent for the removal of lignin through proton-catalyzed hydrolysis of polysaccharides, lignin, and ether or ester bonds in aqueous solution. p- $\mathrm{TsOH}$ has good selective degradation on hemicelluloses and oligosaccharides in the amorphous zone of fiber structure (Bian et al. 2017). $p$-Toluene sulfonic acid removes approximately $85 \%$ of lignin from birch wood after only $20 \mathrm{~min}$ at $80{ }^{\circ} \mathrm{C}$, resulting in a cellulose-rich waterinsoluble solids (WIS) fraction and a spent acid liquor stream containing mainly dissolved lignin (Bian et al. 2017). Due to the low water solubility of $\mathrm{p}-\mathrm{TsOH}$ at ambient temperature, efficient recovery of $\mathrm{p}-\mathrm{TsOH}$ can be achieved by cooling the spent acid solution. This method holds great potential in achieving commercial success.

This research took advantage of the high efficiency of formic acid and its strong reactivity, low price, and good selective degradation on different biomass materials. Formic acid and p-TsOH were mixed and used to separate lignin from poplar material. To use lignin and cellulose obtained from this new fractionation process as raw materials for the production of high-value chemicals in a future biorefinery industry, their structure and properties were characterized by Fourier-transform infrared spectroscopy (FTIR), proton nuclear magnetic resonance ( $\left.{ }^{1} \mathrm{H}-\mathrm{NMR}\right), \mathrm{X}$-ray diffraction (XRD), and scanning electron microscope (SEM). The establishment of an effective fractionation process is also of great significance to the conversion and the utilization of lignin of lignocellulosic biomass. Thus, the optimum conditions of poplar lignin separation were determined. 


\section{EXPERIMENTAL}

\section{Materials}

Analytical grade p-TsOH and 98\% formic acid, purchased from Tianjin Damao Chemical Reagent Factory (Tianjin, China), was used directly without further purification. The poplar wood sawdust was provided by Shandong Chenming Paper Group Co., Ltd. (Shandong, China). The moisture of the poplar wood chips was $2.75 \%$. Chemical analysis showed that it had $40.6 \%$ cellulose, $19.7 \%$ hemicelluloses, and $31.6 \%$ Klason lignin (KL) on a dry weight basis determined by nitric acid - ethanol method by GB/T 745-1989 (1989).

\section{Methods}

Poplar wood sawdust fractionation by mixed $p$-TsOH acid and formic acid

Poplar wood sawdust fractionation by mixed $\mathrm{p}$-TsOH acid and formic acid was conducted in different reaction conditions. The desired concentration and ratio of acid was prepared by mixing the required amounts of $\mathrm{p}-\mathrm{TsOH}$ and formic acid in a three-necked flask. The p-TsOH/formic acid solution in the flask was heated in a water bath to the predetermined temperature (Bian et al. 2017). Next, $5 \mathrm{~g}$ (oven-dry weight) of poplar wood sawdust (the solid-liquid mass ratio was 1:20 $\left(\mathrm{g} \mathrm{mL}^{-1}\right)$ ) was added to the acid solution. The reaction was allowed to proceed according to the pre-designed experimental conditions. At the end of reaction, $100 \mathrm{~mL}$ of distilled and deionized water was added to quench the reaction. A Buchner funnel was used to separate the water-insoluble solid from pulping liquor by vacuum filtration and pressing in order to recover as much lignin as possible. The water-insoluble solid was repeatedly washed to neutral $\mathrm{pH}$ with deionized water and dried at $50{ }^{\circ} \mathrm{C}$ in a convection drying oven (101-2AB, Shanghai Kuntian Laboratory Instrument Co., Ltd.) for $24 \mathrm{~h}$. The filtrate and the washing liquids were evaporated and concentrated to near dryness (black liquor). Water was then poured into the concentrated black liquor to precipitate the dissolved lignin. The crude lignin was separated by centrifugation at $3000 \mathrm{rpm}$ for $10 \mathrm{~min}$ and washed with water three times at room temperature. The crude lignin was purified by washing with deionized water until neutrality and then dried at $50{ }^{\circ} \mathrm{C}$ for $24 \mathrm{~h}$. The effects of acid ratio, acid concentration, reaction temperature, and reaction time on the yield of lignin and solid residues were investigated.

\section{Recovery of formic acid and $p$ - $T s \mathrm{OH}$}

As depicted in Fig. 1, the formic acid and p-TsOH in the waste liquid were recovered by vacuum distillation and crystallization, respectively. After the black liquor was concentrated in an glycerol bath at $100{ }^{\circ} \mathrm{C}$, it was transferred to a RE-52CS rotary evaporator (Shanghai Yanhe Instrument Equipment Co., Ltd, Shanghai, China), where a vacuum degree of $-0.1 \mathrm{MPa}$ and a temperature of $60{ }^{\circ} \mathrm{C}$ was used to recover the formic acid. The $\mathrm{p}-\mathrm{TsOH}$ was recovered using commercially proven crystallization technology by simply cooling the re-concentrated spent acid solution after formic acid recovery as $\mathrm{p}$ $\mathrm{TsOH}$ has low solubility at ambient temperature. The precipitated $\mathrm{p}-\mathrm{TsOH}$ crystals were weighed, and the proportional recovery was calculated. 


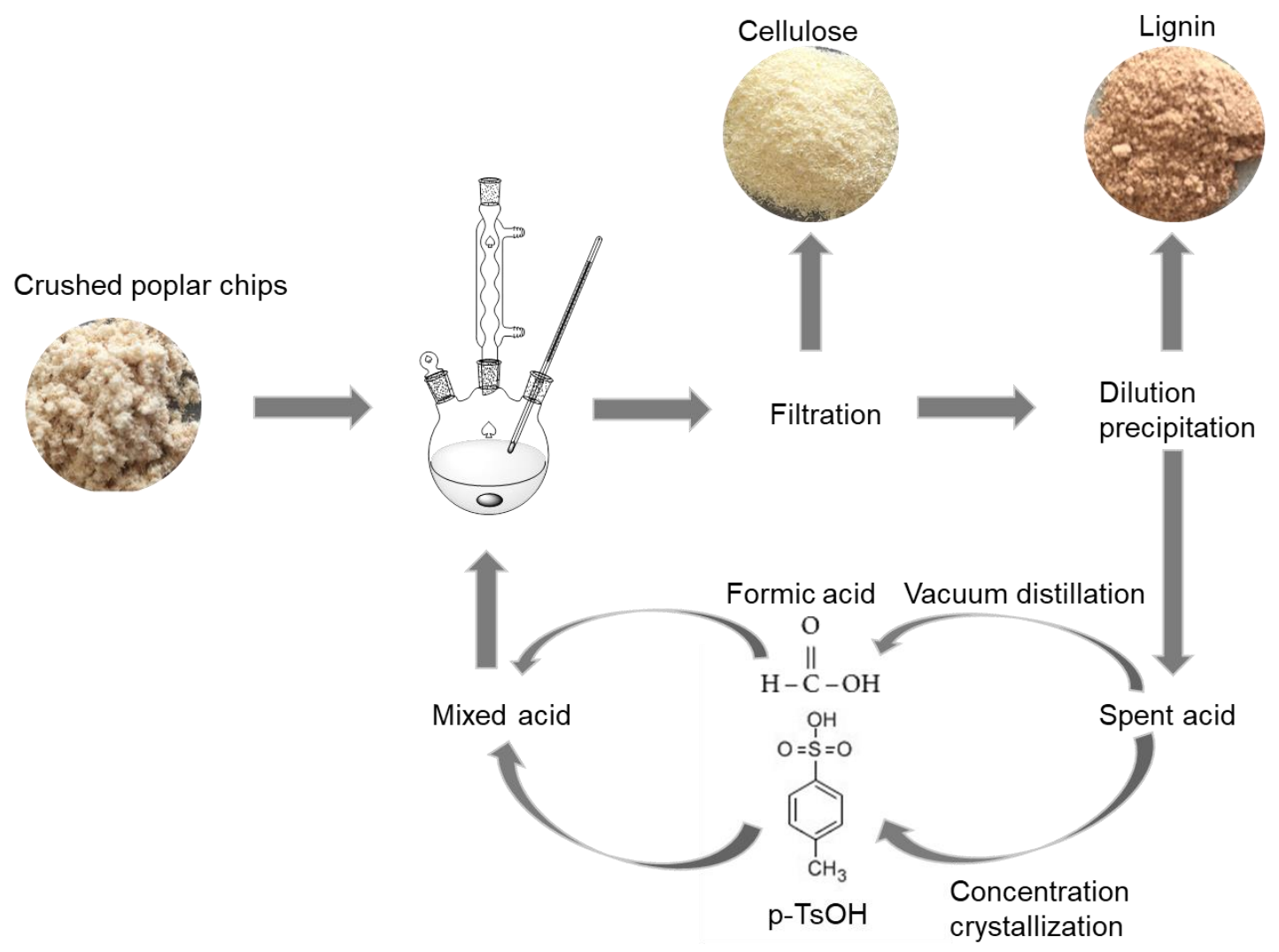

Fig. 1. Schematic diagram of poplar fractionation process

\section{Characterization}

Fourier-transform infrared spectroscopy

The FTIR spectra were collected by Fourier transform infrared spectrometer (VECTOR22, Bruker, Ettlingen, Germany) using a $\mathrm{KBr}$ disc containing finely ground samples (1\%). The resolution of infrared spectrum was $4 \mathrm{~cm}^{-1}$, the collection range was 500 to $4000 \mathrm{~cm}^{-1}$, and the spectrum was obtained from 8 scans in transmission mode.

\section{Nuclear magnetic resonance hydrogen spectrum}

${ }^{1} \mathrm{H}-\mathrm{NMR}$ spectra of the lignin samples dissolved in deuterated dimethyl sulfoxide (DMSO-d6) was recorded by a Bruker Avance II instrument. The samples were scanned at least 8 times with a scanning width of $400 \mathrm{MHz}$, a collection time of $2.0 \mathrm{~s}$, and a relaxation delay time of $3.0 \mathrm{~s}$. All operations were carried out at $25^{\circ} \mathrm{C}$. The spectra were analyzed by MestReNova (Brook, Germany).

Crystallinity indices analysis by X-ray diffraction (XRD)

The crystallinity indices of cellulose were analyzed using wide-angle X-ray diffraction on a Bruker D8 130 Discover system under the condition of $40 \mathrm{kV}, 30 \mathrm{~mA}$, and $\mathrm{Cu}-\mathrm{K} \alpha$ radiation $(I=0.154 \mathrm{~nm})$. Scattering radiation from a pellet made of freeze-dried cellulose was detected in a $2 \theta$ range from $5^{\circ}$ to $60^{\circ}$ in steps of $0.02^{\circ}$ with a scanning speed of $5^{\circ} \mathrm{min}^{-1}$. As previously reported (Segal et al. 1959), the crystallinity index (CrI) of cellulose was calculated as follows,

$$
C r I=\frac{I_{002}-I_{a m}}{I_{002}} \times 100
$$


where $I_{002}$ is the maximum diffraction intensity of the 002 lattice diffraction, and $I_{\mathrm{am}}$ is the diffraction intensity in the same units at $2 \theta=18^{\circ}$.

Scanning electron microscopy

The morphology of poplar cellulose raw fiber, nitrate ethanol cellulose $(\mathrm{C})$ and mixed acid cellulose (MAC) were observed and recorded by JSM-6700F scanning electron microscope (JEOL Ltd., Japan). All SEM samples were sputter-coated with gold to improve the conductivity of the sample and the quality of the SEM image.

\section{RESULTS AND DISCUSSION}

\section{Yields of Water Insoluble Solids (WIS) and Lignin Removal at Different Hydrolysis Conditions}

Figure 2 shows the yields of water insoluble solids (cellulose-rich fraction) and lignin removal at different formic acid and $\mathrm{p}-\mathrm{TsOH}$ acid ratios, acid concentrations, hydrolysis temperatures, and times. The $\mathrm{p}-\mathrm{TsOH} /$ formic acid removed more than $60 \%$ wood lignin with more than $35 \%$ cellulose-rich water-insoluble solids (WIS) under all investigated conditions.

As shown in Fig. 2(a), the change of acid concentration had an influence on the removal of lignin and the yield of water insoluble solids. The increase of acid concentration promoted the fracture of lignin macromolecular ether bond and thus the removal of lignin from the poplar woodchips but caused more cellulose degradation as indicated by the lower WIS yield.

Figure 2(b) shows that the increase of the ratio of mixed acid had little effect on lignin removal but negative effect was observed for cellulose degradation. The higher the concentration of $\mathrm{p}-\mathrm{TsOH}$ in the mix acid resulted in a lower yield of WIS, because of excessive hydrolysis of cellulose. Thus, with the increase of $\mathrm{p}$-TsOH concentration in the mixed acid, more hemicelluloses and some disordered cellulose were hydrolyzed, leading to the reduced yield of WIS (Bian et al. 2017).

Figure 2(c) shows the increase of temperature improved the lignin removal and reduced the yield of water-insoluble solids as more cellulose was degraded. This result indicates $\mathrm{p}-\mathrm{TsOH}$ is not effective in removing lignin and hydrolyzing cellulose at low temperatures even with high concentrations.

Figure 2(d) shows the removal of lignin slightly decreased with the increase of reaction time probably because of the aggregation of dissolved lignin and its deposition on the cellulose surface (Chen et al. 2017). Increased reaction time lowered the yield of water insoluble solid, indicating that more cellulose was degraded (Chen et al. 2016).

The results showed that $84 \%$ lignin was removed when the reaction was carried out at the mass ratio of $\mathrm{p}-\mathrm{TsOH}$ and formic acid of $5: 1$, concentration of $75 \%$, temperature of 80 , and time of $20 \mathrm{~min}$.

\section{Recovery of $\mathrm{p}-\mathrm{TsOH}$ Acid and Formic Acid}

Approximately $36.4 \%$ formic acid and $53.7 \%$ p-TsOH were recovered. 

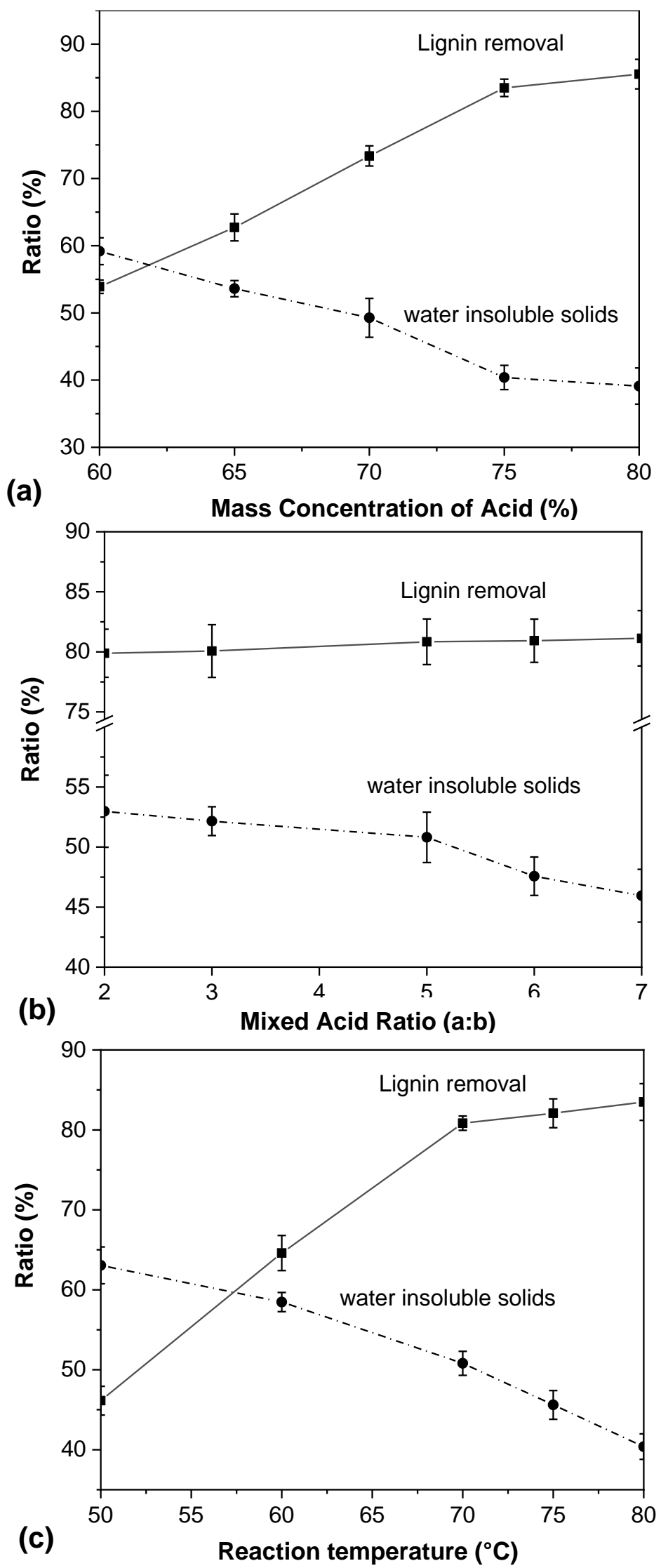


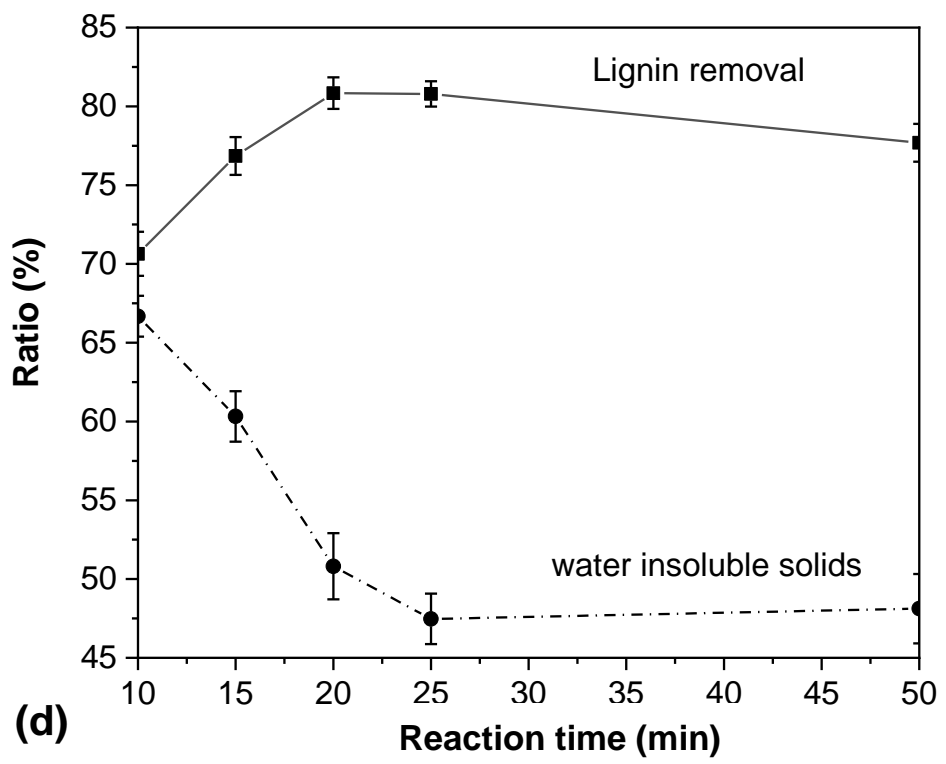

Fig. 2. Yields of water insoluble solids (WIS) and lignin removal at different (a) concentrations of acid, (b) mixed acid ratios, (c) temperatures, and (d) reaction times

\section{Characterization of Solid Residues}

FTIR spectra of solid residues

Figure 3 shows the FTIR spectrum of solid residues from mixed acids treatment. The characteristics of cellulose (Thomas et al. 2015; Benini et al. 2018) are revealed by the presence of the bands associated with the stretching vibration of the $\mathrm{OH}$ group (3408 $\mathrm{cm}^{-1}$ ) and the $\mathrm{CH}$ group $\left(2900 \mathrm{~cm}^{-1}\right)$. Vibration at $1640 \mathrm{~cm}^{-1}$ is associated with $\mathrm{O}-\mathrm{H}$ bond, as cellulose is hydrophilic and interacts strongly with water at the molecular level. No $\mathrm{C}=\mathrm{O}$ group $\left(1717 \mathrm{~cm}^{-1}\right)$ vibration was observed, indicating that no esterification occurred on the cellulose surface.

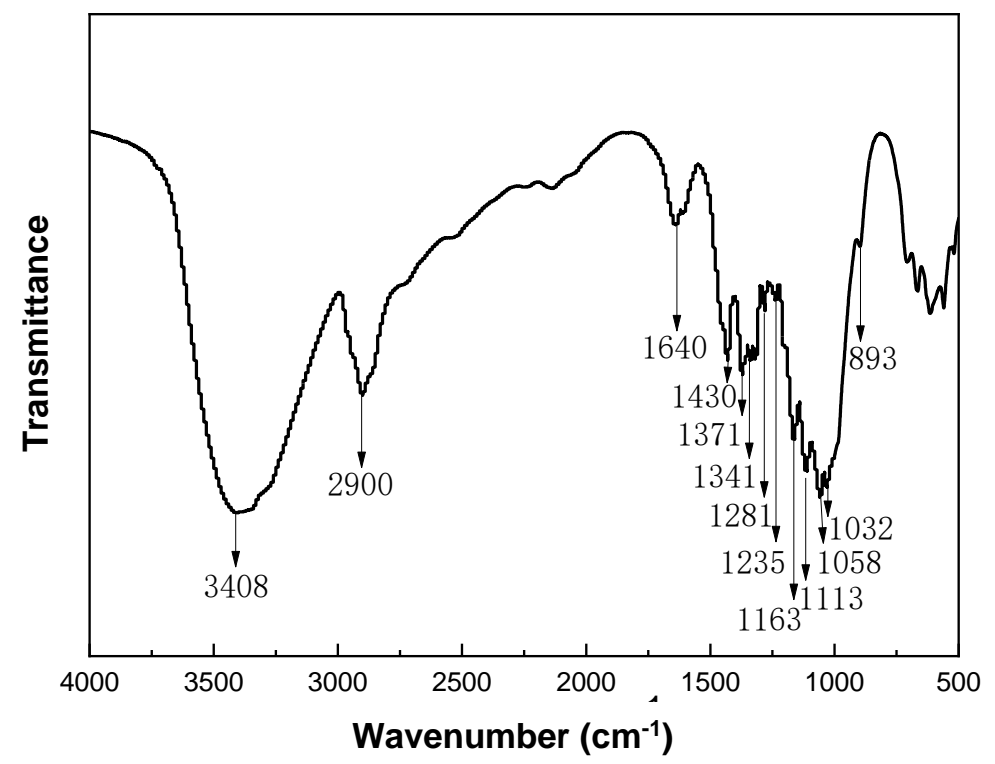

Fig. 3. FTIR spectra of solid residues treated by mixed acid 
The bands at $1430 \mathrm{~cm}^{-1}$ correspond to the crystalline regions in cellulose. In addition, bands corresponding to $\mathrm{C}-\mathrm{H}$ bending vibration $\left(1371 \mathrm{~cm}^{-1}\right)$, to $\mathrm{O}-\mathrm{H}$ or $\mathrm{C}-\mathrm{H}$ bending vibration $\left(1281 \mathrm{~cm}^{-1}\right)$ in arabinoxylan, to C-O stretching vibration $\left(1032 \mathrm{~cm}^{-1}\right)$ in the cellulose, and to $\beta$-glycosidic linkage $\left(893 \mathrm{~cm}^{-1}\right)$ connecting the glucose units in the cellulose were identified.

The FTIR spectra also show characteristic absorption bands of lignin. The band at $1341 \mathrm{~cm}^{-1}$ is attributed to the $\mathrm{C}-\mathrm{O}$ stretching vibration of the ether bond. The band at 1235 $\mathrm{cm}^{-1}$ corresponding to the asymmetric stretching vibration of $-\mathrm{C}=\mathrm{O}$ in the ether, ester, and phenol groups of lignin, $1163 \mathrm{~cm}^{-1}$ and $1058 \mathrm{~cm}^{-1}$ corresponding to the $\mathrm{C}-\mathrm{O}$ stretching vibration, and $1113 \mathrm{~cm}^{-1}$ corresponding to the $\mathrm{C}-\mathrm{H}$ bending in the syringa-base structure of lignin were identified. The presence of these absorption peaks indicates that the cellulose retained a small amount of lignin.

\section{Crystallinity index}

Figure 4 shows measured XRD patterns of the ethanol-nitrocellulose (C) and mixed acid cellulose fibrils (MAC). They had similar diffraction patterns and diffraction angle, grain strength, and crystallization area. At approximately $16.4^{\circ}$ and $22.6^{\circ}$, there are two characteristic peaks corresponding to the (110) and (200) reflective planes of the typical cellulose I structure, revealing that mixed acid hydrolysis did not destroy or alter the intrinsic crystalline structure of the cellulose (Sun et al. 2010; Sun et al. 2007). After mixed acid treatment, the XRD peaks became sharp, especially the diffraction peaks at $2 \theta=16.4^{\circ}$ and $22.6^{\circ}$, indicating that the proportion of the crystalline regions of cellulose increased.

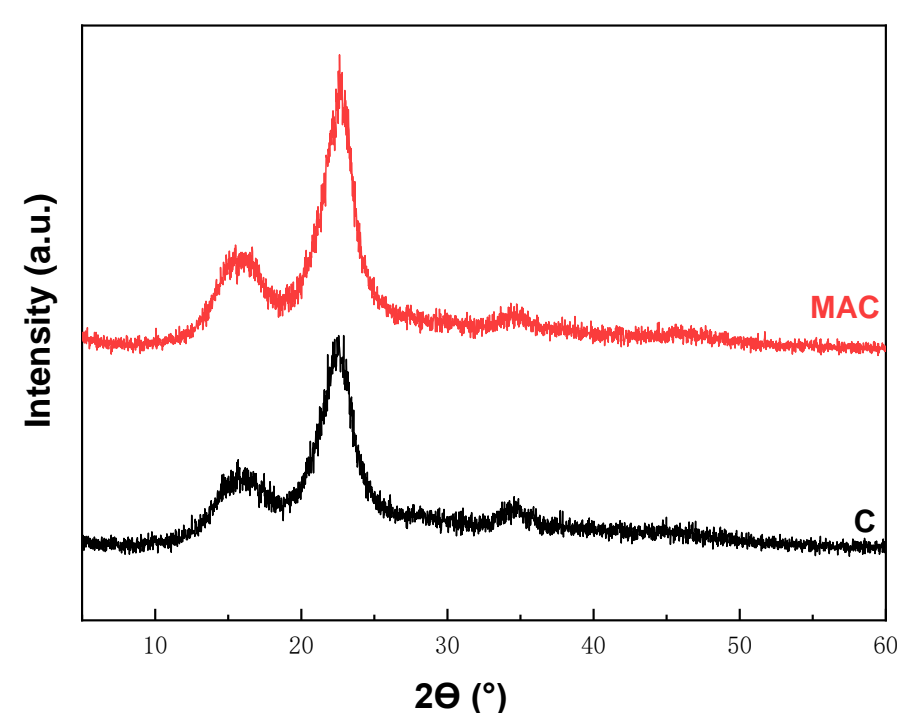

Fig. 4. Measured XRD patterns of ethanol-nitrocellulose (C) and mix acid cellulose fibrils (MAC)

The crystallinity index $(\mathrm{Cr})$ of the cellulose showed that ethanol-nitrocellulose had a crystallinity index of $40.3 \%$ and mixed acid cellulose had a crystallinity index of $58.8 \%$. This result indicated that mixed acid is effective in hydrolyzing the amorphous regions of cellulose and thus producing cellulose with higher crystallinity index.

Scanning electron microscopy 
Figure 5 shows the SEM images of cellulose fibrils, ethanol-nitrocellulose, and solid residues treated by mixed acid at $60{ }^{\circ} \mathrm{C}$ and solid residues treated by mixed acid at 75 ${ }^{\circ} \mathrm{C}$. As shown in Fig. 5 (a), hemicelluloses and lignin are attached to the cellulose before acid treatment. Cellulose structure was clearly exposed after acid treatment as shown in Fig. 5(b), (c), and (d).

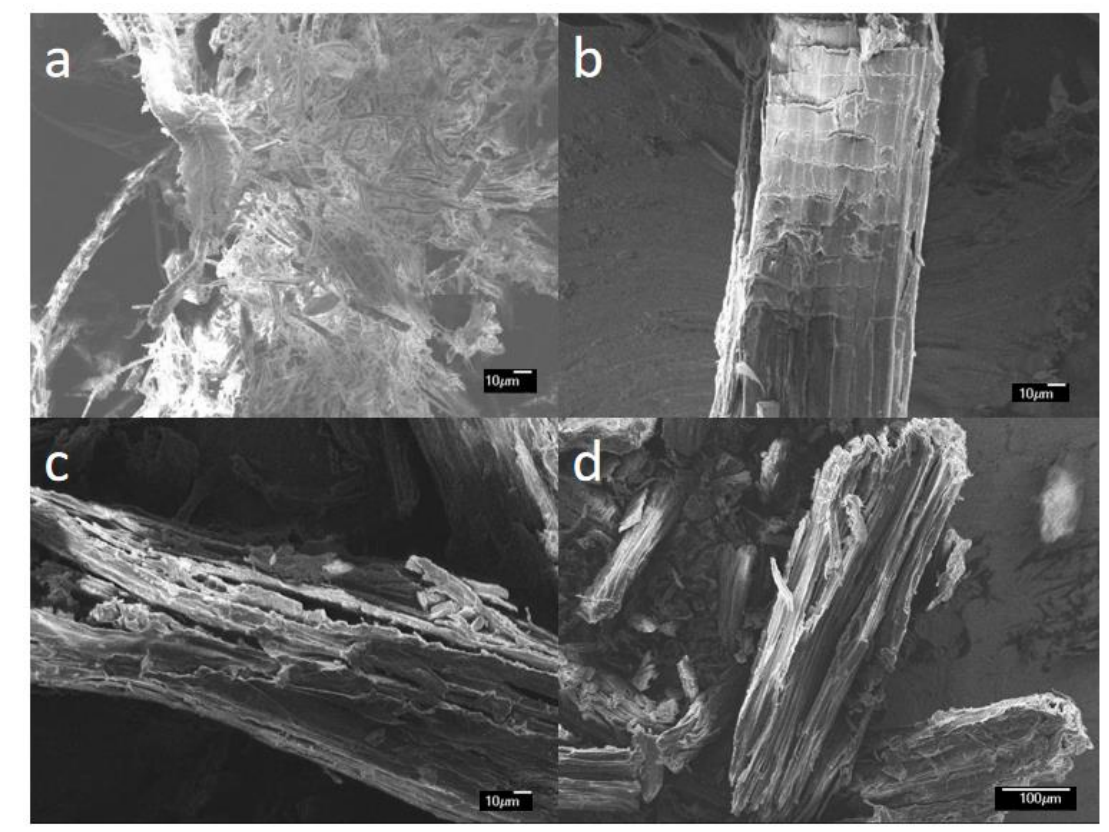

Fig. 5. SEM images of (a) cellulose fibrils, (b) ethanol-nitrocellulose, (c) solid residues treated by mixed acid at $60^{\circ} \mathrm{C}$ and (d) solid residues treated by mixed acid at $75^{\circ} \mathrm{C}$

The surface of the cellulose fibril was more fluffy and rougher than that of ethanolnitrocellulose. Peeling, fluffing, and sliding were observed between the layers after mixed acid treatment due to the efficient removal of hemicelluloses and lignin by mixed acids.

\section{Characterization of Lignin}

FTIR spectra of lignin

The FT-IR spectra of mixed acid lignin (MAL) and KL are shown in Fig. 6. The absorption bands and relative strength of lignin fingerprint regions of both lignins were similar (Zhang et al. 2010). Signals observed at $1607 \mathrm{~cm}^{-1}, 1512 \mathrm{~cm}^{-1}$, and $1422 \mathrm{~cm}^{-1}$ corresponded to the aromatic skeleton vibrations, indicating that the chemical structure of lignin was not changed during the mixed acid treatment process. The band at $3421 \mathrm{~cm}^{-1}$ was assigned to the $\mathrm{O}-\mathrm{H}$ stretching vibration of the phenolic hydroxyl group and the alcoholic hydroxyl group. The bands at $2936 \mathrm{~cm}^{-1}, 2840 \mathrm{~cm}^{-1}$, and $1462 \mathrm{~cm}^{-1}$ corresponded to $\mathrm{C}-\mathrm{H}$ groups of methyl and methylene in lignin. Typical absorption bands of guaiacyl $(\mathrm{G})$ and syringyl (S) of lignin basic units were also found in the FT-IR spectra (Zhang et al. 2017). The absorption peaks at 1330 to $1320 \mathrm{~cm}^{-1}$ corresponded to syringyl (S), and the absorption peaks at 1274 to $1250 \mathrm{~cm}^{-1}$ corresponded to the $\mathrm{C}=\mathrm{O}$ stretching vibration of guaiacyl (G). Compared with KL, the MAL showed a strong absorption peak located at $1714 \mathrm{~cm}^{-1}$, which is the $-\mathrm{C}=\mathrm{O}$ vibration peak of non-conjugated ketones, carbonyl compounds, and ester groups. This might be due to the esterification of the aromatic groups and alcohols in the propane chain during lignin removal (Jahan et al. 2007). 


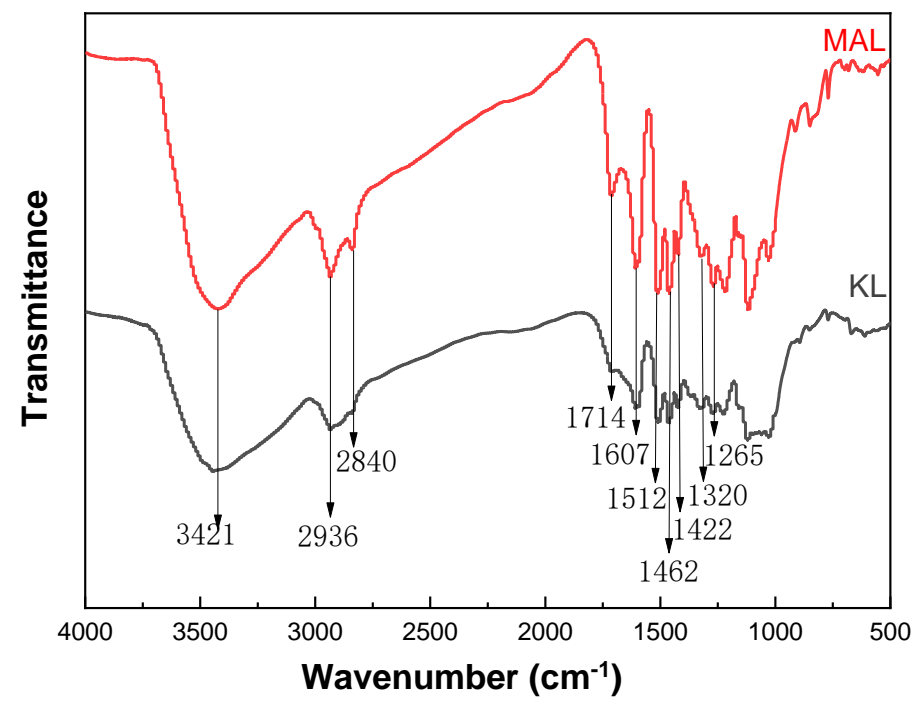

Fig. 6. FTIR spectra of mixed acid lignin (MAL) and Klason lignin (KL)

\section{${ }^{1} H$-NMR spectra of lignin}

The ${ }^{1} \mathrm{H}-\mathrm{NMR}$ spectra of MAL in Fig. 7 shows the aliphatic region $(0.80$ to 3.00 ppm), lignin side chain region (3.00 to $6.00 \mathrm{ppm}$ ), and aromatic region (6.00 to $8.00 \mathrm{ppm}$ ) in lignin. The lignin side chain region includes the methoxy group in the aldehyde group and possible polysaccharides.

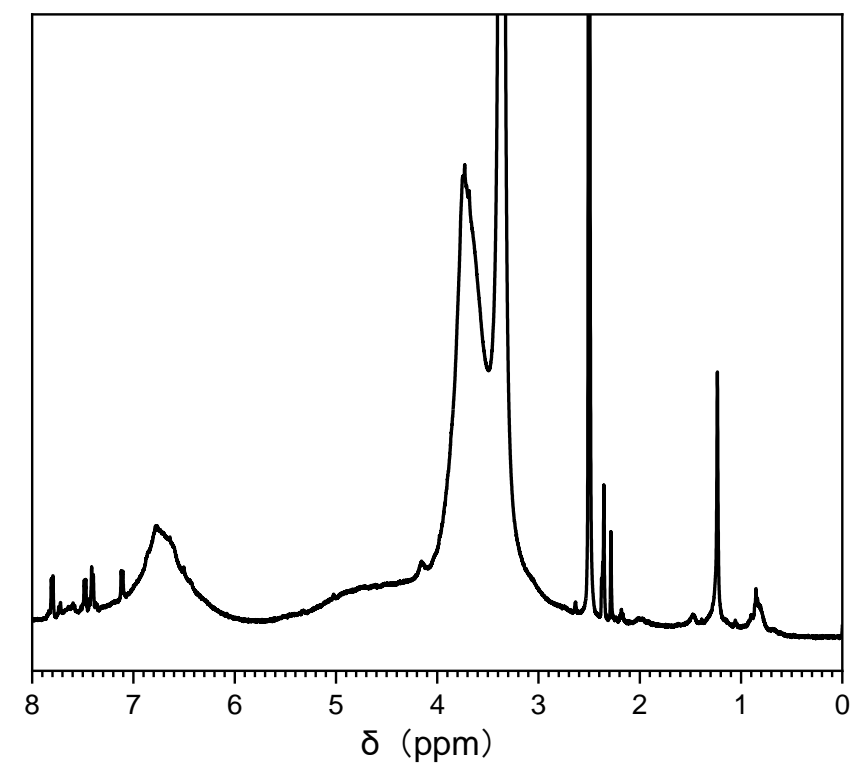

Fig. 7. ${ }^{1} \mathrm{H}$ NMR spectra of mixed acid lignin

Resonance between $7.00 \mathrm{ppm}$ and $8.00 \mathrm{ppm}$ originated from the aromatic protons in the structures of p-hydroxyphenyl $(\mathrm{H})$, p-hydroxycinnamate, and 4-hydroxy-3-methoxy cinnamate. The signal between $6.20 \mathrm{ppm}$ and $6.80 \mathrm{ppm}$ was attributed to aromatic protons in the structures of syclo-propane and guaiac-propane, indicating the relative content of $\mathrm{S}$ and $\mathrm{G}$ in lignin. The signal at $6.78 \mathrm{ppm}$ and $7.44 \mathrm{ppm}$ were associated with hydrogen at $\mathrm{C}$ - 
3 and C-5 positions in the hydroxy cinnamate. The signal at $7.49 \mathrm{ppm}$ originated from the protons at $\mathrm{C}-2$ and $\mathrm{C}-6$ positions in the p-hydroxycinnamate structure. The signal at 7.47 ppm corresponded to the proton at $\mathrm{C}-\beta$ in the hydroxyl cinnamate. The typical resonance of protons on C-6 and C- $\beta$ of 4-hydroxy-3-methoxy cinnamic acid at $6.35 \mathrm{ppm}$ and 7.06 ppm showed did not appear in the ${ }^{1} \mathrm{H}$ spectrum of MAL, indicating the structure of 4hydroxy-3-methoxy cinnamic acid was destroyed during the process of delignification by mixed acid. The signals at $5.58 \mathrm{ppm}$ were attributed to benzyl aryl ether $\mathrm{H}-\alpha$, and the signals between $4.80 \mathrm{ppm}$ and $5.00 \mathrm{ppm}$ corresponded to the $\mathrm{H}-\beta$ of $\beta-\mathrm{O}-4$ 'structure $(\mathrm{Xu}$ et al. 2006). However, these signals did not appear in the spectra of MAL, indicating that the benzyl aryl ether and $\beta$-aryl ether bond were broken during the delignification process. In addition, signals between 0.80 and 2.20 ppm originated from the $\mathrm{CH}_{3}$ and $\mathrm{CH}_{2}$ in $\mathrm{S}$ aliphatic chain of lignin (Oliveira et al. 2009), indicating that the mixed acid treatment process could not remove free fatty acids.

\section{CONCLUSIONS}

1. Poplar wood was fractionated efficiently into lignin and solid residue (mainly cellulose) by mixed acid of para-toluene-sulfonic acid $(\mathrm{p}-\mathrm{TsOH})$ and formic acid at low temperature. At a mass ratio of 5:1 of $\mathrm{p}-\mathrm{TsOH}$ and formic acid, acid concentration of $75 \%$, temperature of $80{ }^{\circ} \mathrm{C}$, and time of $20 \mathrm{~min}$, more than $80 \%$ of the lignin was removed and $50 \%$ of the cellulose was retained as solid residue.

2. Lignin and hemicelluloses that had been present between the fibers was removed by the mixed acid treatment, as characterized by Fourier transform infrared (FTIR) spectrometry, scanning electron microscopy (SEM), and nuclear magnetic resonance (NMR). The crystallinity index of cellulose increased from $40.3 \%$ to $58.8 \%$ after mixed acid treatment.

3. The structure of lignin was changed by mixed acid treatment mainly through destruction of $\beta-\mathrm{O}-4$ ' bonds and 4-hydroxy-3-methoxy cinnamic acid structures in lignin.

\section{ACKNOWLEDGMENTS}

The project is supported by the Foundation of Guangxi Key Laboratory of Clean Pulp \& Papermaking and Pollution Control, College of Light Industry and Food Engineering, Guangxi University (No. 2019KF12), and the Shandong Province of China Key Research and Development Project (No. 2019GGX102026).

\section{REFERENCES CITED}

Achinivu, E. C. (2018). "Protic ionic liquids for lignin extraction - A lignin characterization study," Int. J. Mol. Sci. 19(2), 428-441. DOI: 10.3390/ijms19020428

Achinivu, E. C., Howard, R. M., Li, G., Gracz, H., and Henderson, W. A. (2014). "Lignin extraction from biomass with protic ionic liquids," Green. Chem. 16, 1114-1119.

DOI: $10.1039 / \mathrm{C} 3 \mathrm{GC} 42306 \mathrm{~A}$ 
Benini, K., Voorwald, H. J. C., Cioffi, M. O. H., Rezende, M. C., and Arantes, V. (2018). "Preparation of nanocellulose from Imperata brasiliensis grass using Taguchi method," Carbohydr. Polym. 192, 337-346. DOI: 10.1016/j.carbpol.2018.03.055

Bi, P., Wang, J., Zhang, Y., Jiang, P., Wu, X., Liu, J., Xue, H., Wang, T., and Li, Q. (2015). "From lignin to cycloparaffins and aromatics: Directional synthesis of jet and diesel fuel range biofuels using biomass," Bioresource Technol. 183, 10-17. DOI: 10.1016/j.biortech.2015.02.023

Bian, H., Chen, L., Gleisner, R., Dai, H., and Zhu, J. Y. (2017). "Producing wood-based nanomaterials by rapid fractionation of wood at $80{ }^{\circ} \mathrm{C}$ using a recyclable acid hydrotrope," Green. Chem. 19, 3370-3379. DOI: 10.1039/C7GC00669A

Cai, W., Anderson, E. C., and Gupta, R. B. (2001). "Separation of lignin from aqueous mixtures by ionic and nonionic temperature-sensitive hydrogels," Ind. Eng. Chem. Res. 40, 2283-2288. DOI: 10.1021/ie0009435

Chen, L., Dou, J., Ma, Q., Li, N., Wu, R., Bian, H., Yelle, D. J., Vuorinen, T., Fu, S., Pan, X., and Zhu, J. J. Y. (2017). "Rapid and near-complete dissolution of wood lignin at $\leq 80{ }^{\circ} \mathrm{C}$ by a recyclable acid hydrotrope," Sci. $A d v .3,1-11$. DOI: 10.1126/sciadv.1701735

Chen, L., Zhu, J., Baez, C., Kitin, P., and Elder, T. (2016). "Highly thermal-stable and functional cellulose nanocrystals and nanofibrils produced using fully recyclable organic acids," Green Chemistry 18, 3835-3843. DOI: 10.1039/c6gc00687f

Dapía, S., Santos, V., and Parajó, J. C. (2000). "Formic acid-peroxyformic acid pulping of Fagus sylvatica," Journal of Wood Chemistry and Technology 20, 395-413. DOI: 10.1080/02773810009351891

Dessbesell, L., Paleologou, M., Leitch, M., Pulkki, R., and Xu, C. C. (2020). “Global lignin supply overview and kraft lignin potential as an alternative for petroleum-based polymers," Renew. Sust. Energ. Rev. 123, 109768. DOI: 10.1016/j.rser.2020.109768

GB/T 745-1989 (1989). "Pulps - Determination of pentosan content," Standardization Administration of China, Beijing, China.

Haddad, M., Bazinet, L., Savadogo, O., and Paris, J. (2017). "A feasibility study of a novel electro-membrane based process to acidify Kraft black liquor and extract lignin,” Process Saf. Environ. Prot. 106, 68-75. DOI: 10.1016/j.psep.2016.10.003

Jahan, M. S., Chowdhury, D. A. N., and Islam, M. K. (2007). "Atmospheric formic acid pulping and TCF bleaching of dhaincha (Sesbania aculeata), kash (Saccharum spontaneum) and banana stem (Musa Cavendish)," Ind. Crops Prod. 26, 324-331. DOI: 10.1016/j.indcrop.2007.03.012

Kumar, A., Anushree, Kumar, J., and Bhaskar, T. (2020). "Utilization of lignin: A sustainable and eco-friendly approach,” J. Energy Inst. 1, 235-271. DOI: 10.1016/j.joei.2019.03.005

Kupiainen, L., Ahola, J., and Tanskanen, J. (2012). "Hydrolysis of organosolv wheat pulp in formic acid at high temperature for glucose production," Bioresource Technology 116, 29-35. DOI: 10.1016/j.biortech.2012.04.012

Lam, H. Q., Le Bigot, Y., and Delmas, M. (2001). "Formic acid pulping of rice straw," Industrial Crops and Products 14, 65-71. DOI: 10.1016/S0926-6690(00)00089-3

Li, M.-F., Sun, S.-N., Xu, F., and Sun, R.-C. (2012). "Formic acid based organosolv pulping of bamboo (Phyllostachys acuta): Comparative characterization of the dissolved lignins with milled wood lignin," Chemical Engineering Journal 179, 8089. DOI: $10.1016 /$ j.cej.2011.10.060

Oliveira, L., Evtuguin, D., Cordeiro, N., and Silvestre, A. J. D. (2009). "Structural 
characterization of stalk lignin from banana plant," Ind. Crops Prod. 29, 86-95. DOI: 10.1016/j.indcrop.2008.04.012

Pasquini, D., Pimenta, M. T. B., Ferreira, L. H., and Curvelo, A. A. d. S. (2005). "Extraction of lignin from sugar cane bagasse and Pinus taeda wood chips using ethanol-water mixtures and carbon dioxide at high pressures," J. Supercrit. Fluids. 36, 31-39. DOI: 10.1016/j.supflu.2005.03.004

Rautiainen, R., and Alén, R. (2010). "Characterization of black liquors from kraft pulping of first-thinning Scots pine (Pinus sylvestris L.)," Holzforschung 64,7-12. DOI: 10.1515/hf.2010.005

Sathawong, S., Sridach, W., and Techato, K.-a. (2018). "Lignin: Isolation and preparing the lignin based hydrogel," J. Environ. Chem. Eng. 6, 5879-5888. DOI: 10.1016/j.jece.2018.05.008

Segal, L., Creely, J. J., Martin, A. E., Jr., and Conrad, C. M. (1959). “An empirical method for estimating the degree of crystallinity of native cellulose using the X-ray diffractometer," Text. Res. J. 29, 786-794. DOI: 10.1177/004051755902901003

Sipponen, M. H., Lapierre, C., Mechin, V., and Baumberger, S. (2013). "Isolation of structurally distinct lignin-carbohydrate fractions from maize stem by sequential alkaline extractions and endoglucanase treatment," Bioresource Technol. 133, 522528. DOI: 10.1016/j.biortech.2013.01.175

Snelders, J., Dornez, E., Benjelloun-Mlayah, B., Huijgen, W. J., de Wild, P. J., Gosselink, R. J., Gerritsma, J., and Courtin, C. M. (2014). "Biorefining of wheat straw using an acetic and formic acid based organosolv fractionation process," Bioresource Technology 156, 275-282. DOI: 10.1016/j.biortech.2014.01.069

Sun, Y., and Lin, L. (2010). "Hydrolysis behavior of bamboo fiber in formic acid reaction system," J. Agric. Food. Chem. 58, 2253-2259. DOI: 10.1021/jf903731s

Sun, Y., Lin, L., Pang, C., Deng, H., Peng, H., Li, J., He, B., and Liu, S. (2007).

"Hydrolysis of cotton fiber cellulose in formic acid," Energy Fuels 21, 2386-2389.

DOI: $10.1007 / \mathrm{s} 11461-008-0072-1$

Supanchaiyamat, N., Jetsrisuparb, K., Knijnenburg, J. T. N., Tsang, D. C. W., and Hunt, A. J. (2019). "Lignin materials for adsorption: Current trend, perspectives and opportunities," Bioresource Technol. 272, 570-581. DOI: 10.1016/j.biortech.2018.09.139

Thakur, S., Govender, P. P., Mamo, M. A., Tamulevicius, S., Mishra, Y. K., and Thakur, V. K. (2017). "Progress in lignin hydrogels and nanocomposites for water purification: Future perspectives," Vacuum 146, 342-355. DOI: 10.1016/j.vacuum.2017.08.011

Thakur, V. K., Thakur, M. K., Raghavan, P., and Kessler, M. R. (2014). "Progress in green polymer composites from lignin for multifunctional applications: A review," ACS Sustainable Chem. Eng. 2, 1072-1092. DOI: 10.1021/sc500087z

Thomas, M. G., Abraham, E., Jyotishkumar, P., Maria, H. J., Pothen, L. A., and Thomas, S. (2015). "Nanocelluloses from jute fibers and their nanocomposites with natural rubber: Preparation and characterization," Int. J. Biol. Macromol. 81, 768-777. DOI: 10.1016/j.ijbiomac.2015.08.053

Xu, F., Sun, J.-X., Sun, R., Fowler, P., and Baird, M. S. (2006). "Comparative study of organosolv lignins from wheat straw," Ind. Crops Prod. 23, 180-193. DOI: 10.1016/j.indcrop.2005.05.008

Yasuda, S., Fukushima, K., and Kakehi, A. (2001). "Formation and chemical structures of acid-soluble lignin I: Sulfuric acid treatment time and acid-soluble lignin content of hardwood," J. Wood Sci. 47, 69-72. DOI: 10.1007/BF00776648 
Yuan, T.-Q., He, J., Xu, F., and Sun, R.-C. (2009). "Fractionation and physico-chemical analysis of degraded lignins from the black liquor of Eucalyptus pellita KP-AQ pulping," Polym. Degrad. Stab. 94, 1142-1150. DOI:

10.1016/j.polymdegradstab.2009.03.019

Yuan, T.-Q., Xu, F., and Sun, R.-C. (2013). "Role of lignin in a biorefinery: Separation characterization and valorization," J. Chem. Technol. Biotechnol. 88, 346-352. DOI: $10.1002 /$ jctb.3996

Zhang, M., Qi, W., Liu, R., Su, R., Wu, S., and He, Z. (2010). "Fractionating lignocellulose by formic acid: Characterization of major components," Biomass Bioenergy 34, 525-532. DOI: 10.1016/j.biombioe.2009.12.018

Zhang, Y., Hou, Q., Xu, W., Qin, M., Fu, Y., Wang, Z., Willför, S., and Xu, C. (2017). "Revealing the structure of bamboo lignin obtained by formic acid delignification at different pressure levels," Ind. Crops Prod. 108,864-871. DOI: 10.1016/j.indcrop.2017.08.065

Zhao, X., Cheng, K., and Liu, D. (2009). "Organosolv pretreatment of lignocellulosic biomass for enzymatic hydrolysis," Appl. Microbiol. Biotechnol. 82, 815-827. DOI: $10.1007 / \mathrm{s} 00253-009-1883-1$

Article submitted: February 7, 2021; Peer review completed: February 28, 2021; Revised version received and accepted: March 3, 2021; Published: March 11, 2021.

DOI: 10.15376/biores.16.2.3186-3199 